\title{
TRAMAS DE AFRODITE E EROS: SEDUÇÃO E CAPITULAÇÃO NA MÉLICA GREGA ARCAICA
}

\author{
Giuliana Ragusa $\star$ \\ Universidade de São Paulo
}

\begin{abstract}
This article presents a study of Aphrodite's and Eros's images in archaic Greek melic poetry, in some fragments where the "I", as a result of their divine action, becomes a helpless victim of the power of erotic desire and/or a seducer/seductress in pursuit of the beloved one. These are the melic poets and fragments herein commented: Alcman (Fr. 59(a) Dav.), Sappho (Frs. 1, 102 Voigt), Ibycus (Frs. 286, 288, 287 Dav.).

KEYWORDS: eroticism; archaic Greek melic poetry; Aphrodite; Eros.
\end{abstract}

\footnotetext{
este artigo, percorro fragmentos da mélica (ou lírica) grega arcaica de quatro poetas, Álcman, Alceu, Safo e Íbico, nos quais a $1^{\text {a }}$ pessoa do singular, alvo da ação divina, não apenas se relaciona a Afrodite e/ ou Eros, deidades proeminentes no gênero, mas se torna agente da sedução e/ ou vítima impotente da paixão. ${ }^{1}$
}

\footnotetext{
^gragusa@uol.com.br

${ }^{1}$ Esse artigo dialoga de perto com meus estudos sobre Afrodite na mélica arcaica (Ragusa, G. Fragmentos de uma deusa. A representação de Afrodite na lírica de Safo. Campinas: UNICAMP, 2005/ Ragusa, G. Lira, mito e erotismo. Afrodite na poesia mélica grega arcaica. Campinas: UNICAMP, 2010).
} 


\section{Safo, Frs. 1 e 102 Voigt $^{2}$}

De flóreo manto furta-cor, ó imortal Afrodite, filha de Zeus, tecelã de ardis, suplico-te: não me domes com angústias e náuseas, veneranda, o coração,

mas para cá vem, se já outrora a minha voz ouvindo de longe - me atendeste, e de teu pai deixando a casa áurea a carruagem

atrelando vieste. E belos te conduziram velozes pardais em torno da terra negra rápidas asas turbilhonando, céu abaixo e pelo meio do éter.

De pronto chegaram. E tu, ó venturosa, sorrindo em tua imortal face,

indagaste por que de novo sofro e por que de novo te invoco,

e o que mais quero que me aconteça em meu

desvairado coração. "Quem de novo devo persuadir

(?) ao teu amor? Quem, ó

Safo, te maltrata?

"Pois se ela foge, logo perseguirá;

e se presentes não aceita, em troca os dará;

e se não ama, logo amará, mesmo que não queira".

Vem até mim também agora, e liberta-me dos duros pesares, e tudo o que cumprir meu coração deseja, cumpre; e, tu mesma, sê minha aliada de lutas.

Nesse Fr. 1, a suplicante autonomeada "Safo"3 invoca Afrodite a vir à sua presença - como é típico no hino clético ${ }^{4}$ - para ser sua aliada na sedução da amada (v. 1-5, 25-28) que, no presente, se porta como outra no passado revivido na fala da deusa (v. 21-24). Reportada em

\footnotetext{
${ }^{2}$ Cf. Voigt, E.-M. (Org.). Sappho et Alcaeus. Amsterdam: Athenaeum/ Polak \& Van Gennep, 1971. Para estudo e tradução, cf. Ragusa, op. cit., 2005, p. 261-337/ p. 365-368.

${ }^{3}$ Cf. Skinner [Woman and language in archaic Greece, or, why is Sappho a woman? In: Greene, E. (Org.). Reading Sappho. Berkeley: University of California Press, 1996, p. 183] observa que, dada a função normal do poeta grego arcaico como um falanterepresentante indicado por sua - dele ou dela - comunidade, ébem mais provável que a autoestilização de Safo enquanto o sujeito (ego) que deseja (...) fosse largamente tradicional (...).

${ }^{4}$ Para a prece e o hino clético, um de seus tipos, cf. Bremer [Greek hymns. In: Versnel, H. S. (Org.). Faith, hope and worship. Leiden: Brill, 1981, p. 193-215] e Race (Aspects of rhetoric and form in Greek hymns. GRBS, vol. XXIII, p. 5-6, 1982).
} 
discurso direto, que a presentifica, tal fala é central na prece; nela, as repetições sonoras amarram a declaração de um princípio cujo valor se renova a cada rodada da vivência amorosa da suplicante e, mais amplamente, dos amadores: o "princípio geral de justiça" de Afrodite, diz Carson, ${ }^{5}$ de caráter punitivo-consolatório: na poesia grega antiga, resume, ${ }^{6}$ o consolo dos amadores está na reversão de papéis que a experiência erótica em tempo produz.

O pedido de ajuda na prece vale-se do argumento de que o auxílio divino no passado, nas mesmas condições, para os mesmos fins, implica sua repetição no presente (v. 5-20): a amada reticente de novo deve ser seduzida. Para isso, porém, há que garantir que a ação de éros não torne impotente sua vítima, a suplicante, e que Afrodite seja cúmplice de quem ama e de suas tramas; os versos 1-5 e 25-28 armam esse cenário, levando ao surpreendente epíteto sýmmakhos ("aliada de lutas", v. 28) para a deusa - em única ocorrência na poesia grega ${ }^{7}-$, com o qual a arena erótica se faz marcial.

O binômio opositivo e complementar éros-guerra e seus elos com Afrodite no imaginário poético grego se revelam em vários passos de tons diversos. Na Ilíada (V 428-30), Zeus, divertindo-se com a desastrosa incursão de Afrodite na guerra em Troia, lembra-lhe não ser esta sua esfera de atuação, mas a das bodas. Na Odisseia (VIII 266-366), Demódoco entoa a canção cômica sobre os amantes adúlteros Afrodite e Ares, flagrados pelo marido Hefesto. Na Teogonia (v. 164-206), a castração de Urano gera Afrodite da espuma do pênis e, do sangue, Gigantes, Erínias e guerreiras Ninfas Freixos; adiante, Afrodite ressurge em união erótica com Ares, gerando Fóbos e Deímos, que agem na dissensão da guerra, e Harmonia, que atua na união, própria do sexo (v. 933-937). Noto que Ares e Afrodite são amantes também na iconografia, desde o século VI a.C., e guardam elos na esfera cultual. ${ }^{8}$

\footnotetext{
${ }^{5}$ Cf. Carson, A. The justice of Aphrodite in Sappho 1. In: Greene, E. (org.). Reading Sappho. Berkeley: University of California Press, 1996, p. 227.

${ }^{6}$ Cf. Carson, op. cit., 1996, p. 227-228.

${ }^{7}$ Cf. Campbell, D. A. Greek lyric poetry. London: Bristol, 1998, p. 266.

${ }^{8}$ Tudo isso daria uma faceta guerreira à deusa, ainda que matizada, talvez reminiscente, diz Garrison [Sexual culture in ancient Greece. Norman: The University of Oklahoma Press, 2000, p. 62], da imagem das deusas orientais do sexo, que eram guerreiras; na helenização que engendrou Afrodite, esta foi despida, diz ele, de seu caráter guerreiro, ficando sua afeição por Ares como vestígio de seu poder antigo (op. cit., p. 79).
} 
De volta a Safo, antes de fazer o pedido central, a suplicante empenha-se em implorar a Afrodite (v. 3-4), usando o imperativo para denotar urgência (dámna), que a seu poder não a subjugue com os instrumentos habituais da patologia amorosa: "angústias e náuseas", que comprometem o equilíbrio mental e físico, nos termos originais de som e sentido afinados, ásaisi e oníaisi, respectivamente. Eis aqui a visão poética recorrente de éros como mal que assola corpo e mente. Safo reitera essa visão em sua mélica - lembro a síntese irretocável das dores de amores no célebre Fr. 31; igualmente, os poetas que a precedem e sucedem.

Voltando aos versos 1-2 do hino sáfico, repare-se que a Afrodite chamada na prece é não apenas a olímpica filha de Zeus, dizem o epíteto final do verso 1 e o inicial do 2, mas a belamente multifacetada (Poikilóthron') e a dolóploke ou "tecelã de ardis" Afrodite, cantam o epíteto poético inaugural do verso 1 e o segundo do 2 - aquele nunca mais registrado, este, em apenas três ocorrências. ${ }^{9}$ Amálgamas talvez sáficos, Poikiló-thron' e doló-ploke lançam a sedução erótica e a deidade que a rege no âmbito do movediço, do oblíquo, que é o da métis, a cujo campo semântico pertencem poikilós ("variegado, cambiante") e dólos ("engano, ardil"). A métis, afinal, é a inteligência astuciosa, da dissimulação, da armadilha, do fiar de tramas - inerente à ideia do dolo, implícita em Poikilóthron', explícita em dolóploke, e ao tecer, trabalho feminino por excelência na Grécia antiga, já assim retratado na épica homérica, pelas mãos da bela Helena, das sedutoras Calipso e Circe, e da fiel Penélope.

Na Teogonia (v. 164-206), Hesíodo marca o aspecto enganoso da paixão e, portanto, da deusa, em sua própria gênese, fruto de um terrível ardil maquinado por Terra e executado por Crono, e em suas prerrogativas. Antes disso, a ligação entre a ação de éros e o engano se estabelece claramente no episódio de Diòs Apáte ou "Zeus Iludido", na Ilíada (XIV), ou seja, na sedução do deus por Hera, com a ajuda involuntária de Afrodite e de seu erótico cinto mágico. A arte do engano é, pois, imprescindível na esfera da sedução; e nela ninguém superará Afrodite, preciosa aliada, canta o Fr. 1, de Safo. Diz Garrison: ${ }^{10}$ "Os gregos entendiam todos os seus deuses como enganadores - mas nenhum mais do que Afrodite".

\footnotetext{
${ }^{9}$ Simônides, Fr. $541 \mathrm{P}$ - que fará parte de estudos futuros sobre Afrodite na mélica tardo-arcaica; Fr. 949 P, de autoria desconhecida; Fr. $1386 \mathrm{~W}^{2}$, da Teognideia.

${ }^{10}$ Cf. Garrison, op. cit., p. 40.
} 
Por fim, cabe reparar que há ainda um terceiro universo associado à sedução na canção de Safo, além dos da guerra e do tecer; e é justamente essa imagem da trama de fios, projetada à arena marcial, que o traz à tona: o da caça, no qual a astúcia faz-se necessária, ideia que alavanca a linguagem poética que frequentemente descreve a experiência erótica tanto do ponto de vista do sedutor, quanto do seduzido, mesmo no Fr. 1 (v. 21-24). Não por acaso a poeta usa uma forma de damnáo ao proferir a primeira súplica a Afrodite (v. 3), dado que tal verbo recorre em contextos da guerra e da caça - e no do erotismo, constata-se na Teogonia (v. 122), em que Eros "doma [dámnatai] no peito o espírito e a prudente vontade" de todos os mortais e imortais.

Fundamentalmente, portanto, vemos na prece a suplicante a tentar livrar-se das tramas de Afrodite, em que já capitulou, não para escapar à ação da deidade, mas para dar o passo seguinte: domar nas tramas da sedução, com auxílio da deusa ardilosa e guerreira, a amada - cuja resistência, aceita a prece, está com os segundos contados.

Passo, agora, ao pequeno Fr. 102 Voigt:

Ó doce mãe, não posso mais tecer a trama -

domada pelo desejo de um menino, graças à esguia Afrodite..., ${ }^{12}$

Nele, a filha em $1^{\text {a }}$ pessoa do singular declara à mãe ${ }^{13}$ estar impossibilitada de continuar a trabalhar enquanto estiver subjugada (dámeisa, v. 2) pela ação de uma Afrodite "esguia" - delicada na aparência, mas não na lida com suas vítimas. Essa canção remontaria, na tradição popular, àquelas cujo tema é a "queixa da garota doente de amor", resume Tsagarakis. ${ }^{14}$ Nesse caso, o "eu" pode ser comunal; por isso, Lesky ${ }^{15}$ declara que o fragmento é "um dos exemplos de lírica dramática em

\footnotetext{
${ }^{11}$ Tradução de Torrano (Hesíodo. Teogonia. A origem dos deuses. Tradução e estudo de Jaa Torrano. São Paulo: Iluminuras, 2003); edição de West (Hesiod. Theogony. Edited by M. L. West. Oxford: Clarendon Press, 1988).

${ }^{12}$ Tradução Ragusa, op. cit., 2005, p. 435.

${ }^{13}$ Comenta Tsagarakis (Broken hearts and the social circumstances in Sappho's poetry. RhM. vol. CXXIX, p. 3, 1986): Na sociedade grega antiga, era materna a responsabilidade de determinar o trabalho e os deveres domésticos dos membros de sua família e dos que a ela pertenciam.

${ }^{14}$ Cf. Tsagarakis, op. cit., p. 2.

${ }^{15}$ Cf. Lesky, A. História da literatura grega. Tradução de M. Losa. Lisboa: Calouste Gulbenkian, 1995.
} 
que falam personagens com máscaras alheias”. Assim, o Fr. 102 mostraria que o "eu" dos fragmentos de Safo não é sempre e incondicionalmente "pessoal". Poeta de uma "sociedade orientada em grupos", recorda Lardinois, ${ }^{16}$ Safo, se tanto, "incorpora uma personagem" que, no Fr. 1 e noutros três $(65,94,133)$, se autonomeia "Safo", mas que, na maior parte do que resta de sua mélica, aparece simplesmente como um "eu" que mal se distingue.

Em dois parcos versos, a poeta sintetiza no Fr. 102 um cenário erótico-amoroso muito apropriado a Afrodite, que combina éros ou póthos à ação de subjugar, característica da deusa. Cabe salientar, no verso 1 , que a forma verbal infinitiva kréken ("tecer") e o substantivo íston ("trama") somados lançam de um golpe a canção, num plano explícito, a um universo eminentemente feminino e doméstico, e noutro, implícito, à esfera da dolóploke Afrodite, invocada no Fr. 1. A leitura em viés metafórico daria à canção uma configuração sofisticada, em que são trançados os fios da canção popular de temática sentimental e da mélica erótico-amorosa.

\section{Álcman, Fr. 59(a) Dav.; Íbico, Frs. 286, 287, 288 Dav. $^{17}$}

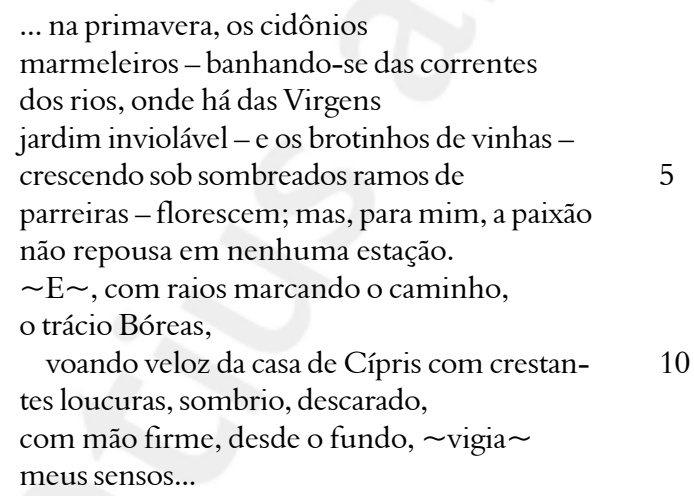

Nesse Fr. 286, de Íbico, a estrutura é parataticamente articulada algo típico da estilística arcaica - e bipartida pela construção sintática mén ... dè, cuja segunda partícula ("mas", v. 6) realça a antítese entre as

\footnotetext{
${ }^{16}$ Cf. Lardinois, A. Who sang Sappho's songs? In: Greene, E. (Org.). Reading Sappho. Berkeley: University of California Press, 1996, p. 159.

${ }^{17}$ Edição Davies (Poetarum melicorum Graecorum fragmenta. Edidit M. Davies. Oxford: Clarendon Press, 1991). Para estudo e tradução, cf. pela ordem dos fragmentos, Ragusa, op. cit., 2010, p. 465-476/p. 394-418/p. 480-507/p. 321-361.
} 
duas partes. Na primeira, no desenho do jardim (v. 1-6), o tempo dominante é o presente que lhe dá a ideia estável de perpetuidade. Afirma, porém, Cavallini, ${ }^{18}$ que esse jardim "coloca-se já na esfera de Eros, de quem representa o aspecto mais próspero e vital, na medida em que é governado pelas sempiternas leis da natureza"; e é éros que se instaura após a pausa no verso 6. Assim, à vernal paisagem sacroerótica, contrapõe-se na segunda parte a invernal e tempestuosa paisagem emocional (v. 8-13); a transição faz-se no prelúdio de "aflita expressão de angústia", frisa Bonelli, ${ }^{19}$ dos versos 6-7, em que o "eu" prepara-se para cantar o terrível inverno na figura do deus Bóreas, gélido vento norte, na concatenação metafórica das imagens tornado a própria paixão ou o próprio deus Eros. ${ }^{20}$

Esse prelúdio é a síntese do desassossego erótico em que se vê presa a persona; e nele, éros (v. 6) sem sossego choca-se com a serenidade do jardim, cortando o fragmento ao meio, praticamente, e dando margem à virada emoì d', que lança ao primeiro plano o "eu" cujo tormento erótico se explicita em notas crescentemente violentas e negativas, que marcam a concepção da paixão em Íbico. O pano de fundo positivo do calmo jardim primaveril (v. 1-6) só agudiza o contraste que a experiência de éros provoca e que a frase emoì d' toma por verdadeiro foco da canção.

Cantam os versos 8-9 que o "trácio Bóreas" vem "com raios marcando o caminho" cujo ponto de origem é - subentende-se - a "casa de Cípris" (v. 10); é de lá que, "voando veloz", ele sai. A imagem só fortalece a proximidade Bóreas/ Eros, e tanto mais se lembrarmos de versos como os de Hesíodo (Os trabalhos e os dias, v. 519-521) e Safo (Fr. 47 Voigt), em que Bóreas ou o vento ligam-se ao erotismo; afinal, é da natureza dos ventos percorrerem paisagens, como forças fertilizadoras. ${ }^{21} \mathrm{Na}$ canção ibiqueia, voa Bóreas/ Eros armado "com crestantes loucuras" (v. 10-11) - de uma secura que queima, diz a imagem contraposta à das correntes abundantes e serenas a banharem, dando-

\footnotetext{
${ }^{18}$ Cf. Cavallini, E. Ibico. Introdução, tradução e comentário de E. Cavallini. Lecce: Argo, 1997, p. 140.

${ }^{19}$ Cf. Bonelli, G. Lettura estetica dei lirici greci. RSC. vol. XXV, p. 81, 1977.

${ }^{20} \mathrm{Cf}$. Calame (The poetics of eros in ancient Greece. Translated by J. Lloyd. Princeton: University Press, 1999, p. 17) e Tortorelli (A proposed colometry of Ibycus 286. CPh, vol. XCIX, p. 371/p. 374, 2004).

${ }^{21}$ Cf. Motte, A. Prairies et jardins de la Grèce antique. Bruxelles: Academie Royale de la Belgique, 1973, p. 10/ p. 208-214.
} 
lhes vida, os marmeleiros do jardim vernal (v. 1-3). Como resume Colonna, ${ }^{22}$ Bóreas "disseca as árvores, como o amor disseca o espírito".

Cabe notar, antes de avançar, o uso de maníaisin ("loucuras"), pois a manía é constantemente relacionada a éros na poesia grega antiga. ${ }^{23}$ Bóreas moldado em Eros chega com "loucuras" que afetam a saúde mental do amador - mais precisamente, com "crestantes loucuras" (v. 10-1), o adjetivo azaléais revelando que o deus-vento e as loucuras que carrega são capazes de queimar, mas com a temperatura glacial própria de sua natureza. Bóreas, ademais, voa da casa de Afrodite "sombrio, descarado" (v. 11). O primeiro termo (eremnós) é dado na Ilíada (XII 375) para o tufão, reforçando a imagem da tempestade invernal trazida por Bóreas/ Eros. Já o segundo (athambés) enfatiza sua temível falta de amarras, seu descaramento - num contraponto ao sentido do adjetivo que qualifica o jardim vernal, akératos, e às "Virgens" a quem pertence.

Em síntese, Bóreas plasmado em Eros é, em Íbico, metáfora da paixão erótica regida por Afrodite. E mais: após afirmar que, para si, éros "não repousa" (v. 7) - literalmente, não "fica no leito" (katákoitos) ${ }^{24}$-, o "eu" canta a vinda de Bóreas/ Eros (v. 8-11) que de pronto se transforma em seu duro algoz (v. 12-3), em nova imagem de carcereiro da persona cuja mente aprisiona em contínua vigilância. Esse motivo do aprisionamento erótico, frequente na poesia grega e latina, se articula à imagem ativa e violenta do Bóreas/ Eros ibiqueu; demais, as conotações militaristas de phylássei ("vigia", v. 12) já antes se insinuam em aísson ("voando veloz, v. 10), de modo que a linguagem de Íbico trabalha, além do binômio paixão-loucura - presente, aliás, no Fr. 1 (v. 17-18), de Safo -, outro igualmente recorrente, paixão-guerra, de que já antes falei. No Fr. 286, de Íbico, portanto, a paixão violenta que se abate sobre a vítima anula "sua habilidade de compreender ou tomar decisões", enfatiza Calame. ${ }^{25}$ No jogo de tensões, não é real o sereno jardim, mas o sofrimento do amador.

\footnotetext{
${ }^{22}$ Cf. L'antica lirica greca. Commento di A. Colonna. Torino: S. Lattes, 1963, p. 218.

${ }^{23}$ A propósito desse binômio, cf. Carson, A. Eros, the bittersweet. Chicago: Dalkey Archive Press, 1998, p. 111-117/p. 148-149/p. 153-155.

${ }^{24}$ Trata-se de um hápax ou unicum, ressaltam Colonna (op. cit., p. 218), Campbell (op. cit., p. 310), Perrotta, Gentili e Catenacci (Polinnia: poesia greca arcaica. Comentário, introdução e traduções de G. Perrotta, B. Gentili e C. Catenacci. Messina: Casa Editrice G. D’Anna, 2007, p. 263).

${ }^{25}$ Cf. Calame, op. cit., p. 17.
} 
Agora, o Fr. 287, síntese bem tramada de motivos recorrentes do erotismo: ${ }^{26}$

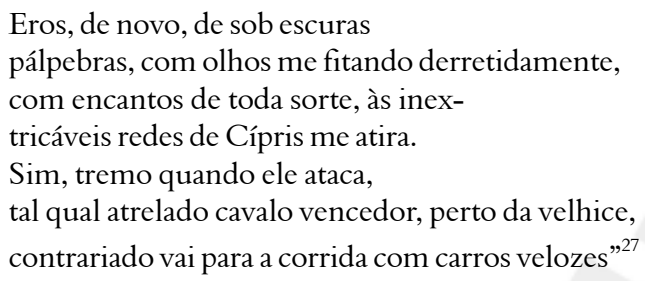

No verso 1, destaca-se â̂te ("de novo), advérbio notável por sua "frequência e pungência", anota Carson, ${ }^{28}$ que faz do evento cantado um episódio (re)vivido. ${ }^{29}$ Essa repetição concerne à experiência erótica - vimos no Fr. 1, de Safo - e marca o modo como o amador em $1^{\text {a }}$ pessoa do singular vê-se vítima "da novidade e da recorrência", conclui Carson. Depois, nos versos 1-2, Eros e sua repetitiva ação se assentam no eixo olhos-olhar; de sob pálpebras ameaçadoras e indicativas do poder do deus que de sob tais pálpebras fita seu objeto como que a fixá-lo (derkómenos).

É uma constante na poesia grega antiga a noção de que o desejo sexual tem os olhos por sede; mostra-o a Teogonia (v. 910-1), na descrição dos olhos das Cárites, de cujas "pálpebras que fitam [derkomenáon], eros escorre,/ o solta-membros [lysimelés] (...)", diz o passo que traduzo mais literalmente. ${ }^{30} \mathrm{~A}$ ação de olhar, em Íbico, como em Hesíodo, é misteriosa e sedutora, e se combina a formas de dérkomai em que o sentido de ver se enfatiza pela intensidade do olhar; ressalta Chantraine ${ }^{31}$ que dérkomai vem do "mesmo radical" de drákon ("serpente"), tendo sempre relação com o "olhar fixo e paralisante" desse réptil. Em Íbico, derkómenos, palavra final do verso 2, subordina-se ao verbo principal, esbállei, última do 4 . Nessa disposição paralela, atrelam-se as duas ações

\footnotetext{
${ }^{26}$ Cf. Campbell (op. cit., p. 66/ p. 311) e Gerber (Euterpe. Comentário de D. E. Gerber. Amsterdam: Adolf M. Hakkert, 1970, p. 216-217).

${ }^{27}$ Tradução Ragusa, op. cit., 2010, p. 650.

${ }^{28}$ Cf. Carson, op. cit., 1998, p. 118.

${ }^{29}$ Cf. Campbell (op. cit., p. 311), Gerber (op. cit., p. 216), Davies (Symbolism and imagery in the poetry of Ibycus. Hermes. vol. CXIV, p. 403, 1986), Perrotta, Gentili e Catenacci (op. cit., p. 265).

${ }^{30}$ Para o texto grego, cf. edição supracitada de West.

${ }^{31}$ Cf. Chantraine, P. Dictionnaire étymologique de la langue grecque. Paris: Klincksieck, 1999.
} 
do deus cujo alvo é o amador. Bem afinada ao aspecto tipicamente sombrio de Eros/ éros em Íbico, no Fr. 287 delineado em seu olhar belo e temível a um só tempo, é a visão do deus como "fitando" (v. 2) sua presa continuamente, expressa o particípio presente derkómenos, e enfaticamente, expressam o instrumento do olhar e seu ponto de partida - "com olhos" e "de sob escuras/ pálpebras" (v. 1-2). Retomando o campo semântico de derkómenos, está claro que da tão fortemente frisada ação de fitar decorre a paralisia temporária da persona, num primeiro passo de sua implacável caça.

Atentemos, agora, para o modo como Eros fita sua presa: defineo takér' (a) ("derretidamente", v. 2), adjetivo em sentido adverbial, a ecoar o recorrente epíteto lysimelés ("dissolve, relaxa, solta membros"), por duas vezes atribuído a Eros/ éros na Teogonia (v. 121, 911). A ideia por trás de ambos os adjetivos é reiterada na poesia grega, como no Fr. 59(a), de Álcman, que liga Eros e Afrodite segundo a hierarquia em que sempre a deusa é superior ao deus, e se assenta na tríade paixão-calorlíquido:

... e Eros, de novo, pela vontade de Cípris,

docemente escorrendo, aquece-me o coração ...

Cabe destacar aqui a abertura de sabor formular Éros me deûte, ${ }^{34}$ que fixa uma apreensão perturbadora da relação entre Eros e suas vítimas por ele reiteradamente assediadas. Pelos desígnios de "Cípris" (v. 2), Eros repetidamente invade o peito da persona de modo doce e aquece seu coração. É doce, portanto, o sabor da recorrente experiência erótica no Fr. 59(a); e é de quentura a sensação da ação de Eros, cujo gatilho é a vontade de Afrodite. Por fim, é motivo frequente o de Eros/ éros qual calor que toma o amador e o liquefaz, mas é Eros/ éros também um líquido que vertem os olhos, já na imagem hesiódica das Cárites, e na própria imagem de Eros no Hipólito, de Eurípides (v. 525-6). Carson avalia: ${ }^{35}$ "Na poesia lírica grega, éros é uma experiência de derretimento"

\footnotetext{
${ }^{32}$ Cf. Carson, op. cit., 1998, p. 115-116, sobre esse epíteto e suas ocorrências.

${ }^{33}$ Tradução Ragusa, op. cit., 2010, p. 641.

${ }^{34}$ Cf. Lasserre, F. La figure d'Eros dans la poésie grecque. Lausanne: Imprimiers Réunies, 1946, p. 33/Privitera, G. A. La rete di Afrodite. Palermo: Aracne, 1974, p. 66-68/Robbins, E. Public poetry. In: Gerber, D. E. (Org.). A companion to the Greek lyric poets. Leiden: Brill, 1997, p. 230.

${ }^{35}$ Cf. Carson, op. cit., 1998, p. 39.
} 
- ambivalente, porque "implica algo sensualmente delicioso, mas ansiedade e confusão com frequência dele tomam parte". ${ }^{36}$ É o que deve ter ocorrido na canção, nos versos seguintes aos que restam do Fr. 59(a).

No Fr. 287, de Íbico, não bastassem seus olhos para derrotar a vítima mortal - impotente por princípio diante do deus -, Eros (v. 3-4) lança-a às redes sem escape de Afrodite - num golpe que sugere violência -, com múltiplos feitiços - novo instrumento de ataque, que firma o elo éros-magia, constante na poesia erótica e no universo de Afrodite desde o episódio da sedução de Zeus na Ilíada (XIV). Se, portanto, no Fr. 286, vimos configurar-se um Bóreas/ Eros qual duro carcereiro de sua vítima, no 287 vemos um Eros caçador-feiticeiro, a prender com violência sua presa numa trama inescapável. O somatório desses elementos produz um resultado evidente: no Fr. 287, a caçada de Eros é a sua chegada com força dominadora e inelutável à persona que fará prisioneira de Afrodite, sua superior hierárquica, em redes que fazem lembrar a que Hefesto preparou e onde prendeu a deusa, sua esposa adúltera, e seu amante, Ares, na canção de Demódoco na Odisseia, já neste artigo referida. Em Íbico, caçado o amador, este se converterá em caçador, lançando-se à sua caçada qual cavalo competidor às corridas, ainda que hesitante pela idade avançada e a experiência de outras competições (v. 5-7). Vale notar que o objeto (a $1^{\text {a }}$ pessoa do singular) do verbo principal esbállei ("atira", v. 4) vem nomeado na abertura do Fr. 287, decerto no embalo da sequência Éros aûté me, de caráter formular, símil à do Fr. 59(a), de Álcman (Éros me deûte).

Recontado o evento-chave da caçada e aprisionamento, a $1^{\text {a }}$ pessoa do singular pensa sua própria condição após a violenta vinda de Eros, com seu ataque que impõe obediência à sua vítima - relutante, porque cônscia da impotência diante do deus, de um lado, e das suas limitações na arena erótica à qual é novamente atirada, de outro. No desenho desse ataque, destaca-se sua nomeação no verbo eperkhómenon ("ataca", v. 5), próprio a contextos marciais, com o qual Íbico reforça o aspecto ameaçador e sombrio do deus ${ }^{37}$ que marcha sobre sua vítima como a tropa sobre seus inimigos. No campo de batalha ou da sedução, não resta senão o pânico, o pavor, que caracterizam a reação da persona à ação de Eros, enfaticamente, na abertura do verso 5: a vítima treme, sabedora de que não tem chance contra a força que recairá sobre si, e da qual tentou, sem sucesso, fugir - daí sua caçada (v. 1-4).

\footnotetext{
${ }^{36}$ Cf. Carson, op. cit., 1998, p. 40.

${ }^{37}$ Cf. Cavallini, op. cit., p. 143.
} 
Nesse contexto, eperkhómenon (v. 5) "funciona como um pivô", diz Davies, ${ }^{38}$ entre as imagens da caçada (v. 1-4) e da corrida de cavalos (v. 6-7). Mais: entre dois pontos de vista sobre a experiência erótica de Eros, agente (v. 1-4), e da persona, vítima da paixão (v. 5-7); entre o temor e a tentativa de fuga e a subordinação à ação divina.

Construído no âmbito agonístico das corridas de carros, o símile do cavalo, fundamental na etapa em que a vítima descreve sua condição, agora que Eros a prendeu nas redes de Afrodite, desenvolve-se a partir do comparativo hóste ("tal qual") que abre o verso 6, o único hexamétrico, de sabor fortemente épico: em ritmo veloz, adequado a tal animal, começa o símile, com o "atrelado cavalo vencedor" em que se transforma a vítima, definida assim como epicamente vitoriosa na arena da sedução, frisa Bonelli. ${ }^{39}$ Logo, porém, a cadência se altera no termo que finda o verso, a anunciar a entrada de tão triunfante animal na "velhice", reduzindo bruscamente seu passo. Nessa mudança, reflete-se o peso dos anos sentido pelo cavalo - pelo amador; ambos são vencedores no jogo que aceitam jogar, mas, próximos à velhice e, aquém de suas forças, só entram em novos combates quando a isso são constrangidos. Entram velozes, sim, diz a escansão do verso 7 - mas mais veloz é Eros.

A relutância do amador explica-se pelo medo da rejeição amorosa, e porque sente que pode não mais estar à altura do fervor da paixão, sugere Falkner; ${ }^{40}$ afinal, "a juventude e a velhice são polos opostos (...)". Acrescenta Finley: "A juventude significava um físico saudável, beleza e atração sexual", ${ }^{42}$ e a tal fase era apropriada à paixão; a velhice significava o contrário de tudo isso. A despeito disso, o amador da canção, como o cavalo, competirá de novo - desta vez, porém, os únicos vencedores são seus caçadores-condutores, Afrodite e Eros. Alinhavado ao símile está, portanto, um motivo revisitado na poesia grega: “(...) o amador ama por necessidade, contra sua vontade e seu bom-senso, e sempre sob o risco da rejeição", resume Falkner, a ecoar a fala de Afrodite no

\footnotetext{
${ }^{38}$ Cf. Davies, op. cit., 1986, p. 403.

${ }^{39}$ Cf. Bonelli, op. cit., p. 85.

${ }^{40}$ Cf. Falkner, T. M. The poetics of old age in Greek epic, lyric, and tragedy. Norman: University of Oklahoma Press, 1995, p. 140.

${ }^{41}$ Finley [cf. Introduction. In: Falkner, T. M.; de Luce, J. (Org.). Old age in Greek and Latin literature. Albany: State University of New York Press, 1989, p. 1] estima que a velhice tenha por faixa etária média no mundo antigo os sessenta anos; mas não sabemos se essa estimativa se verifica já à época de Íbico.

${ }^{42}$ Cf. Finley, op. cit., p. 8.
} 
Fr. 1 Voigt, de Safo. E é notável a competitividade de éros, pois éros "se transforma na arena fundamentalmente aristocrática" da corrida de carros, em que honra e reputação estão em jogo à vista de todos, bem como o valor do cavalo - sinônimo de "elegância, prestígio e coragem", do "prazer de existir", da "alegria do movimento" e da "plenitude física" no mundo heróico, afirma Dumont. ${ }^{43}$

Repare-se, por fim, na conclusão do verso 7, a presentificação da ação no símile - efeito do uso do aoristo gnômico éba ("vai"), comum nos símiles homéricos. ${ }^{44}$ Tal dimensão temporal reforça a ideia inicial, veiculada em aûte ("de novo", v. 1), da repetição no presente de episódios reiteradamente vividos no passado.

Na síntese de Gentili, ${ }^{45}$ portanto, os Frs. 286 e 287 "são construídos segundo uma visão do amor precisa e orgânica, na qual os vários elementos estruturais se articulam em função e em relação à mesma ideia, do caráter anormal, do poder obscuro, obsessivo, de um destino amoroso". Há uma diferença, contudo, no 287: certo humor no símile, sutilmente colocado; afirma MacLachlan: “(...) a triste e algo ridícula figura do velho cavalo de corridas sugere que Íbico, em sua velhice, está se engajando em certa autozombaria" $-{ }^{46}$ em sua velhice ou perto dela, como creio (v. 6).

$\mathrm{Na}$ trama da canção de Íbico, o amador é vítima da ação direta do deus, indireta da deusa. Segundo enfatiza MacLachlan, o motivo "do amador como presa, ou do jogo amoroso como caçada, era caro aos poetas gregos da paixão, ocorrendo pela primeira vez" no Fr. 287; e "era popular entre os poetas romanos também", conclui. Ambos os lados de tal motivo são articulados no fragmento: Eros é o caçador ativo do amador (erastés); e este é a presa habilmente caçada, que - ainda que constrangido a isto - certamente sairá no encalço de seu amado (erómenos). No fragmento, Eros nada diz; quem fala é o amador - decerto ao objeto que deseja seduzir e a quem se revela em sua subjugada e ardente, não obstante algo extemporânea, paixão. Tal objeto deve ser, como nos Frs. 286 e 288, o paîs kalós ("belo menino"), alvo das palavras

\footnotetext{
${ }^{43}$ Cf. Dumont, J. Les animaux dans l'Antiquité grecque. Paris: L'Harmattan, 2001, p. 52.

${ }^{44}$ Cf. Campbell (op. cit., p. 311), Perrotta, Gentili e Catenacci (op. cit., p. 266).

${ }^{45} \mathrm{Cf}$. Gentili, B. Metodi di lettura (su alcune congetture ai poeti lirici). QUCC. vol. IV, p. 179, 1967.

${ }^{46}$ Cf. MacLachlan, B. Personal poetry. In: Gerber, D. E. (Org.). A companion to the Greek lyric poets. Leiden: Brill, 1997, p. 196.
} 
encantatórias - recorde-se o uso de "encantos" $\left(\right.$ kelémasi $\left.^{47}\right)$ no verso 3 do Fr. 287, como arma de Eros - do sedutor, postas em canção que o auxiliará nas novas conquistas às quais se vê lançado a contragosto.

Essa leitura, projetada já para a performance e para o próprio gênero do Fr. 287, provavelmente um paidikón - como o $286-,{ }^{48}$ encontra reforço na sugestão de Parry, ${ }^{49}$ segundo quem formas e termos ligados a keléo, como o adjetivo do verso 3 da canção de Íbico, constituem "essencialmente um grupo de metáforas para o poder 'encantador' da música em geral e de quaisquer palavras organizadas ritmicamente". Com seus encantos, produzidos por sua canção, o amador, ele próprio presa de Eros e Afrodite, deseja atirar na mesma prisão o amado; símil ao cavalo vitorioso e engajado na corrida, poderá ser bem-sucedido na caçada, como são os deuses, seus caçadores.

Finalmente, trato do Fr. 288 Dav., de Íbico, outro paidikón - canção de um adulto que faz o elogio do paîs kalós ("belo menino") que quer seduzir -, que nos lança à esfera erótica e simposiástica tão trabalhada na poesia grega antiga:

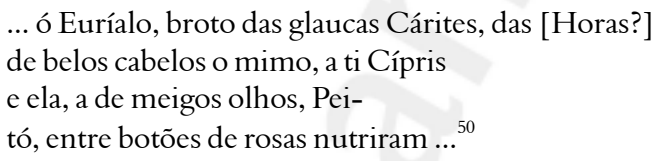

A qualificação de Euríalo de pronto abre a linguagem altamente metafórica dos versos, baseada na ideia do crescimento ou renovação vegetal; o sujeito invocado é, em suma, um menino agraciado por deusas que, tanto na poesia quanto nos cultos, ligam-se ao vicejar das plantas

\footnotetext{
${ }^{47}$ Conforme Parry (Thelxis. Lanham: University Press of America, 1992, p. 24), kelémasi deriva de keléo, verbo que aparece tanto nas formas mais arcaicas de mágica, quanto nas mais tardias; Chantraine dá-lhe o sentido de "encantar", "em princípio, com palavras ou cantos".

${ }^{48} \mathrm{O}$ fragmento é citado na fonte (Banquete dos sofistas 601b-c, Ateneu, séculos II-III d.C.) na discussão sobre éros, para ilustrar o tema do poder de Eros e Afrodite (599f) e o gênero do paidikón (601a), canção de um adulto que faz o elogio do "belo menino" (paîs kalós) que quer seduzir.

${ }^{49}$ Cf. Parry, op. cit., p. 24.

${ }^{50}$ Tradução Ragusa, op. cit., 2010, p. 650-651. A favor do suplemento do verso 1, "Horas", cf. Campbell (op. cit., p. 312), Davies (op. cit., 1986, p. 404), Cavallini (op. cit., p. 83/p. 144/ p. 147) e Brillante (Linquietante belleza di Eurialo. RCCM. vol. XL, 1998, p. 15).
} 
ou dos mortais, à alegria, à graça física, à sedução, à persuasão. Tendo capitulado diante de sua figura - os olhos, anota Brillante, ${ }^{51}$ cumprem "importante função de mediação entre amador e amado", pois são a porta de entrada da paixão -, o adulto deseja seduzir o divino Euríalo, por isso louvado na encantadora e encantatória canção, e invocado qual deus no verso 1.

O cenário do Fr. 288 parece sereno, à diferença dos cenários dos Frs. 286 e 287. Aparências enganam, contudo; indica-o fortemente o grupo de deusas que protegem e nutrem o menino, que recorda o da criação de Pandora n'Os trabalhos e os dias:

$$
\begin{aligned}
& \text { deusas Graças [Cárites] e soberana Persuasão [Peitó] em volta } \\
& \text { do pescoço puseram colares de ouro e a cabeça, } \\
& \text { com flores vernais, coroaram as bem comadas Horas ... }
\end{aligned}
$$

Como seria o caso no Fr. 288, as Horas são ditas kallíkomoi no poema hesiódico, e se associam às Cárites e a Peitó. Além disso, elas integram o séquito de Afrodite, na iconografia, na poesia, nos cultos. A similaridade repercute ainda no sentido: o passo acima conta como foi gerada a primeira mulher, irresistível tormento, bem e mal aos homens, "enganador presente" de Zeus, diz Lyons; $;^{53}$ o belo Euríalo será, igualmente, doce e amargo tormento.

Essa expectativa só se agrava se atentarmos para suas nutrizes, que alimentam Euríalo com arrebatadora beleza física: as próprias deusa da persuasão e do sexo. E ainda para o leito de sua nutrição, "entre botões de rosas" (v. 4); ora, na poesia, Afrodite está muito próxima da vegetação e das flores, e a rosa é uma flor consagrada à deusa na religião, na iconografia e na poesia. Além disso, as rosas delicadamente adicionam ao cenário mais um elemento sombrio, que nos remete à percepção negativa da paixão em Íbico. Como bem salienta Irwin, ${ }^{54}$ a rosa dos poetas e dos artistas gregos antigos é a "flor selvagem que crescia nos arbustos e era notável tanto por sua fragrância, quanto por seus espinhos”. O toque macio de suas pétalas e o aroma doce que delas se

\footnotetext{
${ }^{51}$ Cf. Brillante, op. cit., p. 13.

${ }^{52}$ Cf. Hesíodo. Os trabalhos e os dias. Tradução de M. C. N. Lafer. São Paulo: Iluminuras, 2002; texto grego da edição de West.

${ }^{53}$ Cf. Lyons, D. Dangerous gifts. ClAnt. vol. XXII, p. 99, 2003.

${ }^{54}$ Cf. Irwin, E. The crocus and the rose. In: Gerber, D. E. (Org.). Greek poetry and philosophy. Chicago: Scholars Press, 1984, p. 161.
} 
desprende são o contraponto prazeroso dos ferimentos que seus espinhos podem provocar; o toque da pele tenra e do corpo fragrante do belo menino Euríalo é, como o da rosa e de Afrodite, fonte de prazer e de dor - em Íbico, sobretudo de dor.

Um último detalhe chama a atenção no cenário de Íbico: são "botões de rosas" (v. 4) que o compõem; tal qual o Euríalo-broto, as rosas em meio às quais as deusas o nutrem estão por desabrochar. Que não haja engano: o perigo potencial das belezas do menino e da rosa em botão pode ainda lhes ser subjacente, mas está à espreita de quem delas se aproxima demais - como o adulto que canta o paidikón para arrebatar Euríalo, diante de quem capitulou e a quem busca fazer sucumbir à sedução.

No Fr. 288, em síntese, no centro das atividades das deidades da juventude e do erotismo está Euríalo, "broto" de umas, "mimo" de outras, nutrido por outras ainda, num leito de rosas em botão - imagem que desperta os sentidos do tato, da visão e do olfato, e que, arrematando o quarteto de versos num crescendo, torna o menino, já divinamente belo e desejável, simplesmente irresistível e, por isso, perigoso ao amador que projeta em linguagem metafórica uma beleza que a linguagem denotativa não é capaz de exprimir, a fim de elogiar Euríalo para seduzi-lo.

As Cárites, Peitó e Cípris são nutrizes do belo Euríalo, nutrizes da paixão, logo, do desassossego do amador, que se intensifica na medida em que, frisa Bowra, ${ }^{55}$ Íbico se dirige ao menino "quase como um poeta mais arcaico se dirigiria a um deus (...)”, de tal sorte que Euríalo projeta "menos uma criatura da terra" do que um ser divino. De fato, como diz Brillante, ${ }^{56}$ Euríalo "foi objeto da máxima atenção e obteve o resultado mais alto"; ele, complete-se, parece plasmado em Eros-menino, amante das flores e belíssimo, a quem Afrodite, em certa iconografia, amamenta, qual kourotróphos. Isso quer dizer que o poder que a beleza de Euríalo tem de suscitar a paixão e o inevitável sofrimento dela advindo é infalível: o amador está perdido.

Como bem mostra esse percurso que aqui se finda, de Eros e de Afrodite, não há quem escape ileso; e bem sabiam disso os poetas.

\footnotetext{
${ }^{55}$ Cf. Bowra, C. M. Greek lyric poetry. Oxford: Clarendon Press, 1961, p. 258.

${ }^{56}$ Cf. op. cit., p. 14
} 


\section{Referências}

BONELLI, G. Lettura estetica dei lirici greci. RSC.v. XXV, p. 65-94, 1977.

BOWRA, C. M. Greek lyric poetry. Oxford: Clarendon Press, 1961.

BREMER, J. M. Greek hymns. In: VERSNEL, H. S. (Org.). Faith, hope and worship. Leiden: Brill, 1981.p. 193-215.

BRILLANTE, C. L'inquietante belleza di Eurialo. RCCM.v. XL, p. 13-20, 1998.

CALAME, C. The poetics of eros in ancient Greece. Translated by J. Lloyd. Princeton: University Press, 1999.

CAMPBELL, D. A. Greek lyric poetry. London: Bristol, 1998.

CARSON, A. The justice of Aphrodite in Sappho 1. In: GREENE, E. (Org.). Reading Sappho. Berkeley: University of California Press, 1996. p. 226-232.

. Eros, the bittersweet. Chicago: Dalkey Archive Press, 1998.

CAVALLINI, E. Ibico. Introdução, tradução e comentário de E. Cavallini. Lecce: Argo, 1997.

CHANTRAINE, P. Dictionnaire étymologique de la langue grecque. Paris: Klincksieck, 1999. DAVIES, M. Symbolism and imagery in the poetry of Ibycus. Hermes. v. CXIV, p. 399-405, 1986.

DUMONT, J. Les animaux dans l'Antiquité grecque. Paris: L'Harmattan, 2001.

Euterpe. Comentário de D. E. Gerber. Amsterdam: Adolf M. Hakkert, 1970.

FALKNER, T. M. The poetics of old age in Greek epic, lyric, and tragedy. Norman: University of Oklahoma Press, 1995.

FINLEY, M. I. Introduction. In: FALKNER, T. M.; de LUCE, J. (Org.). Old age in Greek and Latin literature. Albany: State University of New York Press, 1989. p. 1-20.

GARRISON, D. H. Sexual culture in ancient Greece. Norman: The University of Oklahoma Press, 2000.

GENTILI, B. Metodi di lettura (su alcune congetture ai poeti lirici). QUCC.v. IV, p. 177-181, 1967.

Greek melic poets. Introdução, edição e comentário de H. W. Smith. New York: Biblo and Tannen, 1963.

HESÍODO. Os trabalhos e os dias. Trad. C. N. Lafer. São Paulo: Iluminuras, 2002.

Teogonia. A origem dos deuses. Tradução e estudo de Jaa Torrano. São Paulo: Iluminuras, 2003.

. Theogony. Edited by M. L. West. Oxford: Clarendon Press, 1988.

.Works and days. Edited by M. L. West. Oxford: Clarendon Press, 1982.

IRWIN, E. The crocus and the rose. In: GERBER, D. E. (Org.). Greek poetry and philosophy. Chicago: Scholars Press, 1984. p. 147-168.

LAFER, M. de C. N. Introd., trad., notas. Hesíodo. Os trabalhos e os dias. 4. ed. São Paulo: Iluminuras, 2002. 
L'antica lirica greca. Commento di A. Colonna. Torino: S. Lattes, 1963.

LARDINOIS, A. Who sang Sappho's songs? In: GREENE, E. (Org.). Reading Sappho. Berkeley: University of California Press, 1996. p. 150-172.

LASSERRE, F. La figure d'Eros dans la poésie grecque. Lausanne: Imprimiers Réunies, 1946. LESKY, A. História da literatura grega. Trad. M. Losa. Lisboa: Calouste Gulbenkian, 1995. LYONS, D. Dangerous gifts. ClAnt. v. XXII, p. 93-135, 2003.

MACLACHLAN, B. Personal poetry. In: GERBER, D. E. (Org.). A companion to the Greek lyric poets. Leiden: Brill, 1997. p. 133-220.

MOTTE, A. Prairies et jardins de la Grèce antique. Bruxelles: Academie Royale de la Belgique, 1973.

PARRY, H. Thelxis. Lanham: University Press of America, 1992.

PIRENNE-DELFORGE, V.L'Aphrodite grecque. Athènes: CIERGA, 1994.

Poetarum melicorum Graecorum fragmenta. Edidit M. Davies. Oxford: Clarendon Press, 1991.

Polinnia: poesia greca arcaica. Comentário, introdução e traduções de G. Perrotta, B. Gentili e C. Catenacci. Messina: Casa Editrice G. D’Anna, 2007.

PRIVITERA, G. A. La rete di Afrodite. Palermo: Aracne, 1974.

RACE, W. H. Aspects of rhetoric and form in Greek hymns. GRBS. v. XXIII, 1982, p. 5-14.

RAGUSA, G. Fragmentos de uma deusa. A representação de Afrodite na lírica de Safo. Campinas: UNICAMP, 2005. (Apoio: Fapesp)

.Lira, mito e erotismo. Afrodite na poesia mélica grega arcaica. Campinas: UNICAMP, 2010. (Apoio: Fapesp)

ROBBINS, E. Public poetry. In: GERBER, D. E. (Org.). A companion to the Greek lyric poets. Leiden: Brill, 1997. p. 221-288.

SKINNER, M. B. Woman and language in archaic Greece, or, why is Sappho a woman? In: GREENE, E. (Org.). Reading Sappho. Berkeley: University of California Press, 1996, p. 175-192.

TORTORELLI, W. A proposed colometry of Ibycus 286 . CPh. v. XCIX, p. 370376, 2004.

TSAGARAKIS, O. Broken hearts and the social circumstances in Sappho's poetry. RhM, v. CXXIX, p. 1-17, 1986.

VOIGT, E.-M. (Org.). Sappho et Alcaeus. Amsterdam: Athenaeum/ Polak \& Van Gennep, 1971. 